\title{
CONF-9410189--8
}

UCRL-JC-117086

PREPRINT

\section{High Rate PLD of Diamond-Like-Carbon Utilizing Copper Vapor Lasers}

RECEIVED

NOV - 31995

\author{
William McLean II \\ Edward J. Fehring \\ Ernest P. Dragon \\ Bruce E. Warner
}

This paper was prepared for submittal to the ICALEO '94

Orlando, Florida

October 17-20, 1994

August 15, 1994

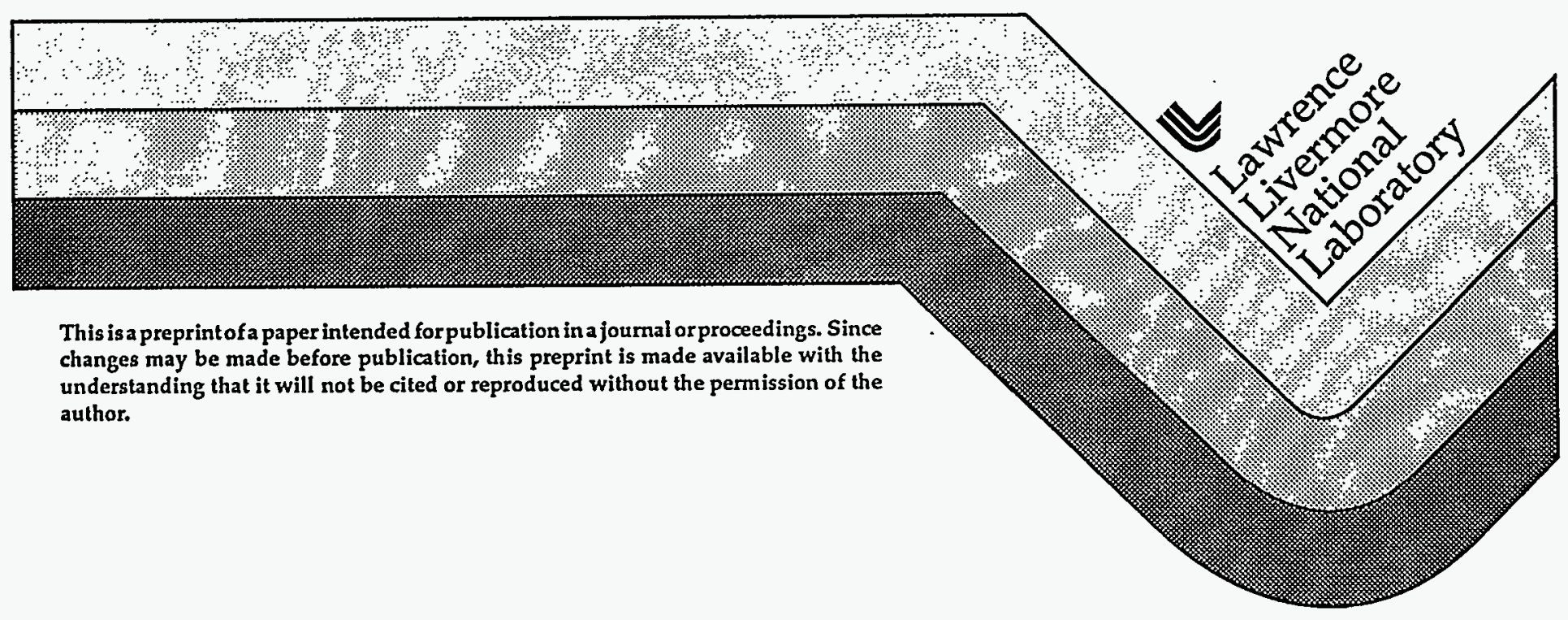

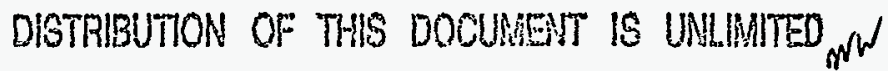

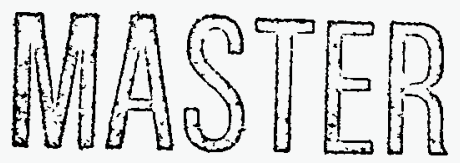




\section{DISCLAMMER}

1. This document was prepared as an account of work sponsored by an agency of the United States Government. Neither the United States Government nor the University of California nor any of their employees, makes any warranty, express or implied, or assumes any legal liability or responsibility for the accuracy, completeness, or usefulness of any information, apparatus, product, or process disclosed, or represents that its use would not infringe privately owned rights. Reference herein to any specific commercial product, process, or service by trade name, trademark, manufacturer, or otherwise, does not necessarily constitute or imply its endorsement, recommendation, or favoring by the United States Government or the University of California. The views and opinions of authors expressed herein do not necessarily state or reflect those of the United States Government or the University of California, and shall not be used for advertising or product endorsement purposes. 


\title{
High Rate PLD of Diamond-Like-Carbon Utilizing Copper Vapor Lasers
}

\author{
William McLean II, Edward Fehring, Ernest Dragon, Bruce Warner \\ University of California \\ Lawrence Livermore National Laboratory \\ P. O. Box 808 , L-466 \\ Livermore, CA 94551 \\ Tel: 510-422-9237 Fax: 510-423-7651
}

\begin{abstract}
Thin film formation by pulsed laser deposition (PLD) has been routinely demonstrated at the laboratory scale for many elements and compounds. In order for processes based on PLD to progress from bench top experiments to commercialization, a number of key issues must be resolved. The principal limitations of current PLD technology are low deposition rate, inclusion of macro particles in the film that are ejected from the target, and difficulty in producing uniform coatings over large areas. Only thin films of very high value are considered economic at present deposition rates, of order $10 \mu \mathrm{m}-\mathrm{cm}^{2} / \mathrm{h}$. Recently, a significant increase in PLD rate has been achieved in our laboratory, over $2000 \mu \bullet \mathrm{cm}^{2} / \mathrm{h}$. These rates were accompanied by good surface characteristics by utilizing a copper vapor laser, operating at $100 \mathrm{~W}$ to $200 \mathrm{~W}$ average power and $4.3 \mathrm{kHz}$ pulse repetition rate. The initial system demonstrations were performed by depositing high quality diamond-like-carbon (DLC) films with a remarkably low level of macro particle inclusions. The experiments and material characterizations performed on the deposited material are reviewed here.
\end{abstract}

\section{Introduction}

Many high-value coatings have been produced by PLD. Examples are: high Tc superconductors $\left(\mathrm{YBa}_{2} \mathrm{Cu}_{3} \mathrm{O}_{7}\right),{ }^{1}$ ferroelectric films for nonvolatile memories $\left(\mathrm{Pb} \mathrm{Zr}_{\mathrm{x}} \mathrm{Ti}_{1-\mathrm{x}} \mathrm{O}_{3}\right),{ }^{2}$ low work function field emitters (DLC), ${ }^{3}$ tribiological coatings (DLC), ${ }^{3}$ cutting tool coatings (cubic BN), ${ }^{4}$ optical coatings ( $\mathrm{BaTiO}_{3}$ and $\left.\mathrm{TiO}_{2}\right), 5$ and biocompatible ceramics (calcium hydroxylapatite) ${ }^{6}$ The majority of studies utilize short wavelength (193 nm [ArF] to $308 \mathrm{~nm}$ [XeCl]) light arriving in $20-50 \mathrm{~ns}$ pulses with peak irradiances of $10^{8}-10^{10} \mathrm{~W} / \mathrm{cm}^{2}$ at rates of $5-30 \mathrm{~Hz}{ }^{1-6}$ However, some authors report positive results with green ( $532 \mathrm{~nm}$ [frequency doubled Nd:YAG]) radiation sources operated under similar conditions. ${ }^{7}$ Typical film formation rates are on the order of $10 \mu \mathrm{m}-\mathrm{cm}^{2} / \mathrm{hr}^{1-6}$

One of the distinct advantages of the PLD process is the near stoichiometric transfer from the ablation target to the desired substrate, a feature that is often difficult to achieve with conventional 
coating technologies such as magnetron sputtering or electron beam evaporation. In many cases, minor:adjustments to the substrate temperature and/or background pressure of reactive gases result in adherent coatings with acceptable morphologies, correct stoichiometries, and desirable physical properties. The main impediments to large scale commercialization are the high cost, low power, and low pulse repetition rates of readily available laser systems.

Our original experiments were guided by information gathered in the literature and by colleagues in the field of PLD. Conventional wisdom based on $\mathrm{CO}_{2}, \mathrm{Nd}$ :YAG and excimer laser experiments indicates deposition of DLC is most successful (in terms of film quality) when the target is irradiated with ultraviolet light. ${ }^{8}$ The higher the photon energy, the higher the diamond like content of the coating. Murray, ${ }^{8}$ has measured the population of ions of carbon polymers in the ablation plume with a time-of-flight mass spectrometer and has concluded that $193 \mathrm{~nm}$ generated plasmas have predominantly $\mathrm{C}^{+}$ions, where as the $1064 \mathrm{~nm}$ generated plasmas have predominantly $\mathrm{C}_{11}{ }^{+}$ $\mathrm{C}_{13}{ }^{+}$ion content. Other researchers claim that both $\mathrm{Nd}: Y A G$ and $\mathrm{CO}_{2}$ lasers can produce good material if the irradiance is $10^{10} \mathrm{~W} / \mathrm{cm}^{2}$ or higher.3a These findings are phenomenologically explained by a dominant atomic carbon plasma of high kinetic energy created by laser absorption directly into the carbon plume.

\section{Experimental Arrangement}

A single copper vapor laser (CVL) oscillator and one high power amplifier were used for these studies. Nominal operating parameters are summarized in Table 1 . The optical delivery system was comprised of a discrete optics delivery system and a single $500 \mathrm{~mm}$ focusing lens located adjacent to the vacuum deposition tank. Relatively low irradiance $\left(10^{8} \mathrm{~W} / \mathrm{cm}^{2}\right)$ on the target was necessary to achieve high deposition rates and good materials properties. This was accommodated by defocusing the beam on the target.

Table 1. Operating Parameters.

Wavelength:

Spot size on target:

Irradiance

Pulse width:

Target speed:

Target - Substrate Distance:

DLC deposition rate:
$510,578 \mathrm{~nm}(2: 1)$

$50-300 \mu \mathrm{m}$

$2 \times 10^{10}-4 \times 10^{8} \mathrm{~W} / \mathrm{cm}^{2}$

$50 \mathrm{~ns}$ (FWHM)

$8 \mathrm{~cm} / \mathrm{s}$

$7.6 \mathrm{~cm}$

$5.6 \times 10^{-2} \AA /$ pulse at $4 \times 10^{8} \mathrm{~W} / \mathrm{cm}^{2}$

$1.0 \times 10^{-3} \AA$ pulse at $2 \times 10^{10} \mathrm{~W} / \mathrm{cm}^{2}$

A schematic drawing of the deposition chamber is shown in Fig. 1. The laser light is introduced through a fused silica window. The graphite target is a rod of 1 inch diameter that is mechanically rotated at approximately 1 RPS and can be manually moved axially to keep a relatively fresh surface. The laser is aligned to strike the rod off center so that the laser plume is at 45 or 60 degrees to the incident beam. In general, the ablation plumes expand normal to the surface. The substrate to be coated is mounted within a sample port that is easily removed for deposition on multiple substrates. The graphite target to substrate distance is $7.6 \mathrm{~cm}$. Viewports orthogonal to the laser and plume and in the scattered laser direction were used to help diagnose laser alignment, plume generation, and qualitatively assess macroparticle generation. A turbomolecular pump was used to achieve a base pressure of $5 \times 10^{-8}$ Torr. For each set of deposition runs the vacuum chamber was heated up and outgassed. Typical vacuum levels during deposition episodes were in 


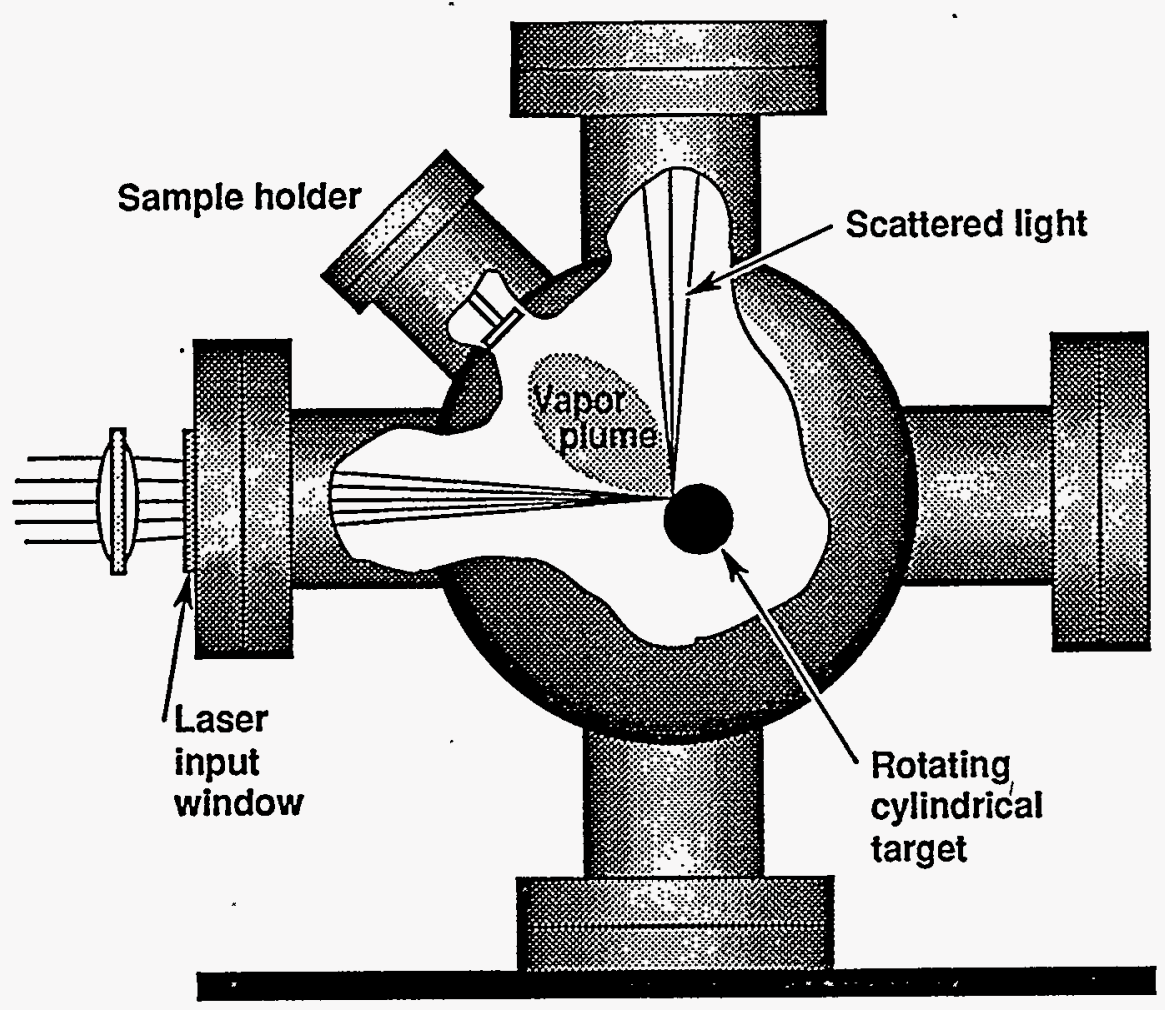

Figure 1. Developmental PLD chamber schematic.

the $10^{-6}$ Torr range. To date, no assist or buffer gases have been used. Several different substrates have been coated with DLC. However, consistent with results of others, adherence of the films are substrate dependant.

Our first indication of high deposition rate was observed after 10 seconds of PLD. The fused silica window to the chamber suffered reduced transmission of the input laser beam due to coating by DLC. (DLC can have a significant loss in the visible spectrum depending on the percentage of graphitic-carbon content and thickness of coating). This coating was very difficult to remove and required repolishing of the window. For early deposition runs, input windows were routinely replaced. Subsequently, the window was extended from the chamber to a $330 \mathrm{~mm}$ standoff. This allowed operation of approximately 40 seconds between window changes. This experience has led to a conceptual design of a protected window, discussed in a later section.

\section{Deposition Results}

Our early experiments investigated the deposition of DLC at laser irradiance of $10^{8} \mathrm{~W} / \mathrm{cm}^{2}$ to $10^{10} \mathrm{~W} / \mathrm{cm}^{2}$. Figure $2 \mathrm{a}$ and $2 \mathrm{~b}$ are Elastic Electron Loss Spectroscopy (EELS) spectra performed on the resultant material (a) and on a graphite substrate (b). Typically there are three predominant features in an EELS DLC spectra. The elastic electron scattering peak is at the incident electron energy; in Fig. 2, $500 \mathrm{eV}$. There is a peak $\sim 6.6 \mathrm{eV}$ below the incident energy which represents energy lost to the $\pi$-bonds of graphite (at $494 \mathrm{eV}$ in Fig. 2). The third feature is an unresolved, broad plasma loss peak 30 to $40 \mathrm{eV}$ below the incident energy. The DLC represented in Fig. 2a was deposited on a polished $\mathrm{Si}(100)$ substrate at a laser irradiance of $3 \times 10^{8} \mathrm{~W} / \mathrm{cm}^{2}$. Note the lack of a $\pi-\pi^{*}$ feature as compared to the graphite spectra in Fig. $2 \mathrm{~b}$. This material's spectra is 
similar to that of material produced by Murray with $193 \mathrm{~nm}$ wavelength light. Researchers in the field have also used Raman scattering off of the DLC films to help quantify its bond structure.? Figure 3 is a representative Raman spectra of our DLC film grown with the above paramenters. This spectra verifies the DLC nature of the film.
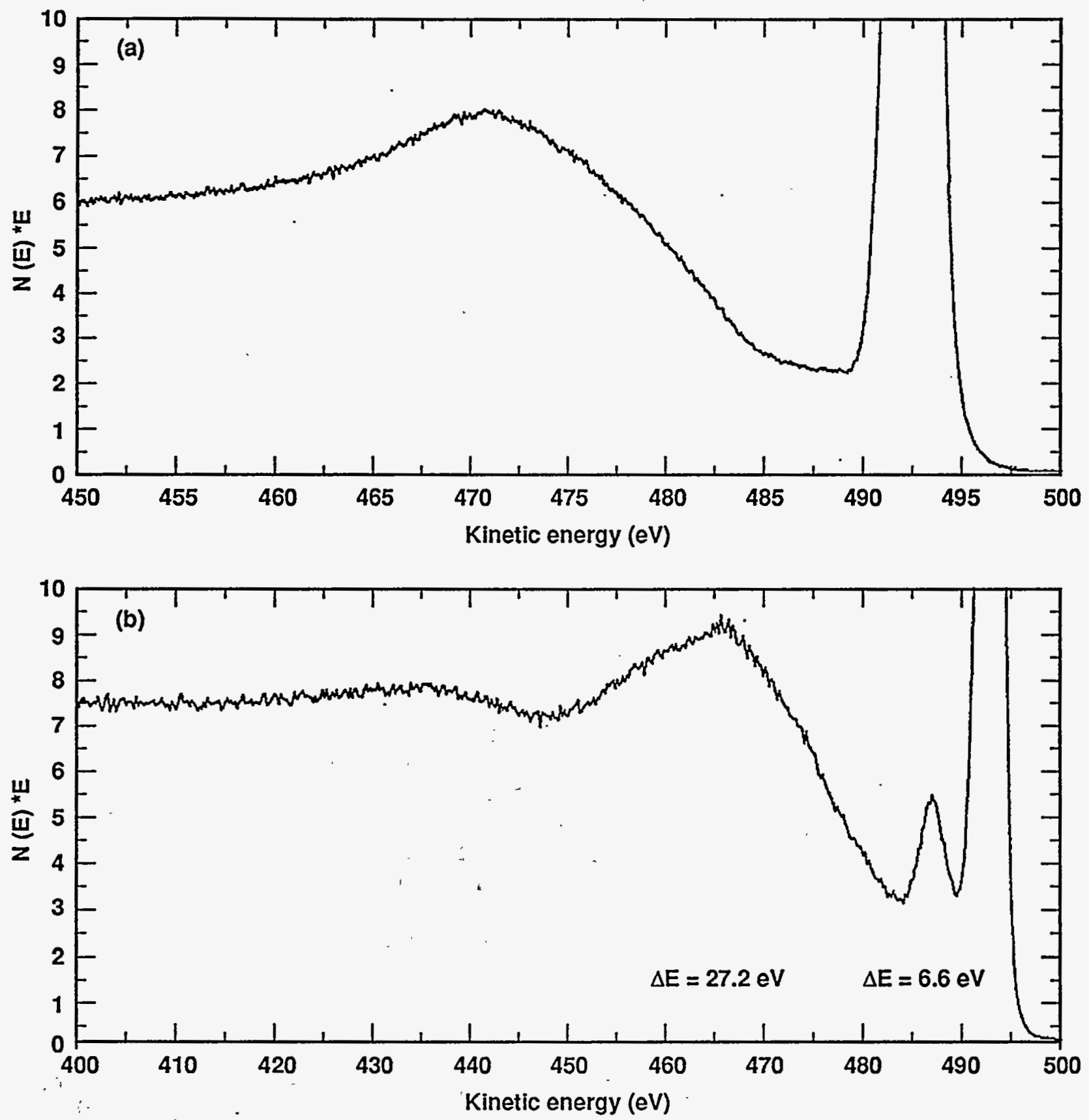

Figure 2. (a) EELS spectra of DLC produced at $3 \times 10^{8} \mathrm{~W} / \mathrm{cm}^{2}$. (b) EELS spectra of graphite.

The (silicon) substrates were masked while both the target irradiance and number of laser pulses were controlled to quantify the volume of DLC grown on the substrates. Its spatial distribution and its growth rate were determined by measuring film thickness and distribution with a diamond 
stylus profilometer at the step-up provided by the masked area. Figure 4 displays a measured DLC deposition thickness across the substrate. The deposition has a very peaked character typical of PLD. It is this peaked film deposition that makes uniform film growth over large areas difficult.

The deposition profile in Fig. 4 has been fit with a plume distribution proportional to $\cos ^{10.5}$ $\phi\left(\phi\right.$ is the angle measured from the target surface normal). After $10^{5}$ laser pulses at $4 \times 10^{8} \mathrm{~W} / \mathrm{cm}^{2}$ ( $190 \mathrm{~W}$ average power), we achieved $410 \mathrm{~nm}$ thickness at the center with half thickness at a radius of $\sim 4 \mathrm{~cm}$. Since the copper lasers operate at $4.4 \mathrm{kHz}, 10^{5}$ pulses represents 23 seconds of elapsed time. Integrating the full volume of material and dividing by the elapsed time yields an average deposition rate of $2 \times 10^{3} \mu-\mathrm{cm}^{2} / \mathrm{hr}$. We have subsequently operated at $100 \mathrm{~W}$ average power at slightly lower target irradiance and have achieved $2.6 \times 10^{3} \mu-\mathrm{cm}^{2} / \mathrm{hr}$. At this rate we produce DLC coatings in minutes that would normally take hours by either low repetition rate lasers or RF plasma deposition (note that materials can have significantly different properties with $R F$ plasma deposition). We have recently produced a $2.5 \mu \mathrm{m}$ thick DLC film on a silicon substrate, with good surface characteristics. This film was grown with 58 seconds of laser on time.

Atomic Force Microscopy (AFM) was used to measure surface roughness. Figure 5 displays an AFM image of the DLC surface. The area depicted in the image is 0.5 by $0.5 \mu \mathrm{m}$. Note that the vertical scale is $20 \mathrm{~nm}$ per division. This $400 \mathrm{~nm}$ thick DLC film has a surface roughness (as measured by the AFM) of $\leq 10 \mathrm{~nm}$. We have produced some films with RMS surface roughness as low as a few nanometers.

Tool steel and tungsten carbide were coated as a demonstration of potential value to the machine tool and industrial processing industry. In our two attempts to coat the tool steel we have not been able to achieve good adherence. This has been observed by others. ${ }^{10}$ The adhesion to steels seems to be related to the degree of saturation of the $4 \mathrm{~d}$ or $5 \mathrm{~d}$ bonds in the substrate material. ${ }^{11}$ Steels with high carbon content (and metal carbides) are less likely to form carbides with the newly deposited carbon and, therefore, are better substrates for diamond formation. The DLC we deposited on a tungsten carbide tool bit survived the scotch tape test. The tool bit was subsequently sent out for further analysis. In the areas of the bit that were smooth enough to perform scratch tests upon, the DLC had excellent adherence.

\section{Discussion}

There are three observations we have made that add to the base of knowledge of PLD. First, visible light under our operating conditions appears to produce DLC with characteristics as good as material produced with ultraviolet sources. If these results hold with further investigation, it could greatly simplify large scale PLD equipment. Either copper vapor or Q-switched and doubled Nd:YAG lasers operated at high repetition rate should be much more readily incorporated into a thin film production line than ultraviolet sources. Visible light is easily delivered through optical fibers at high enough radiances to be used in PLD. 


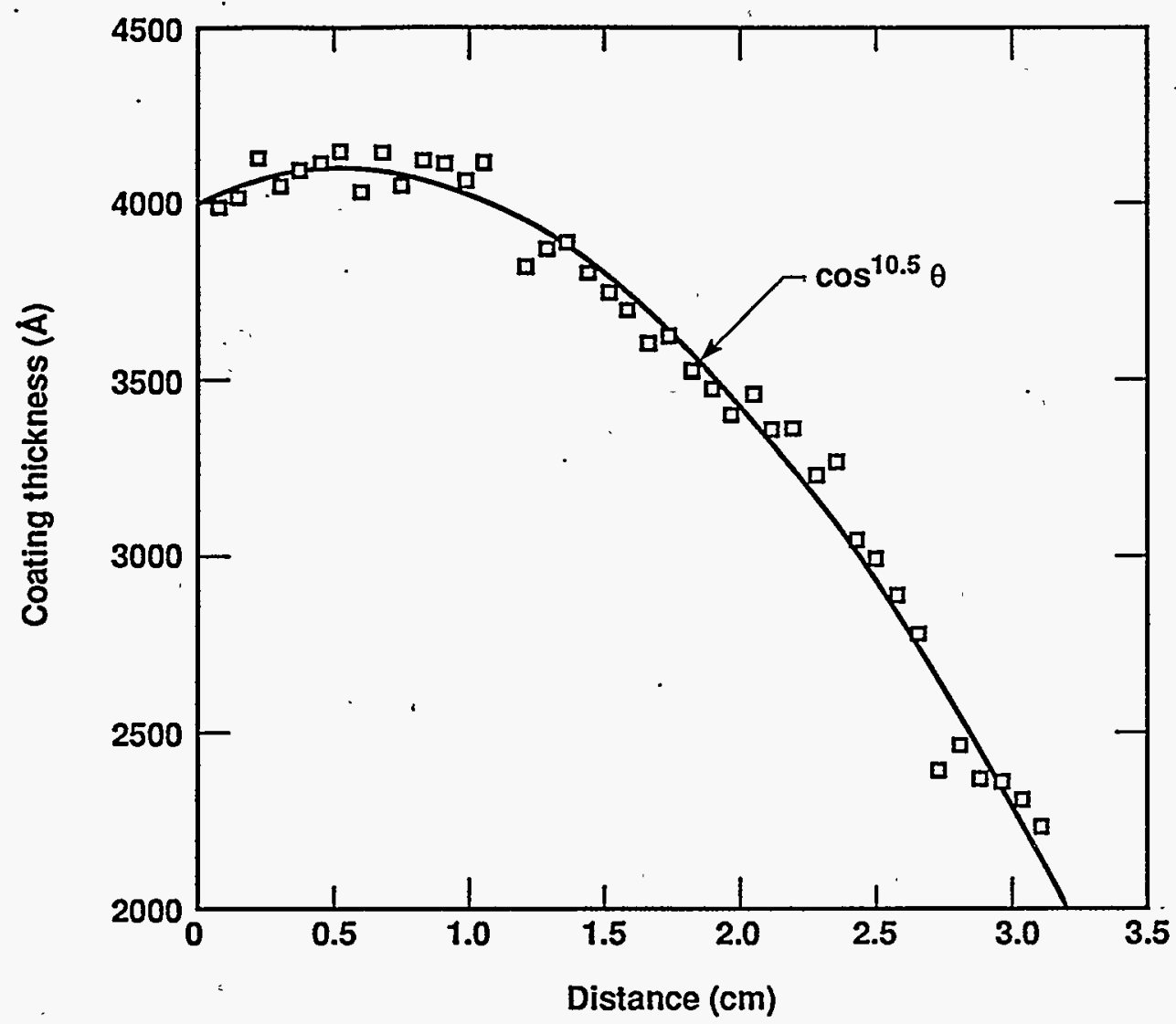

Figure 3. Typical PLD deposition profile.

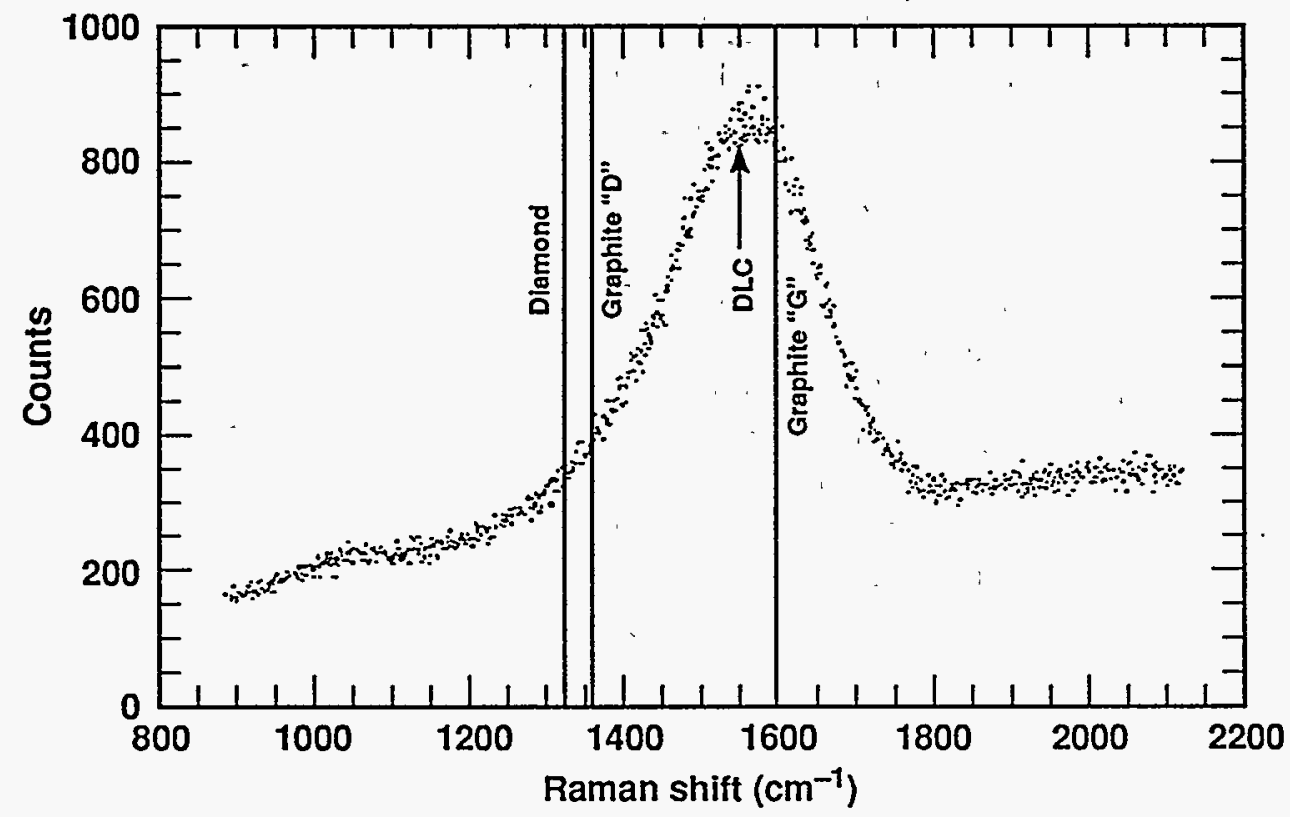

Figure 4. Raman spectrum of DLC film. 


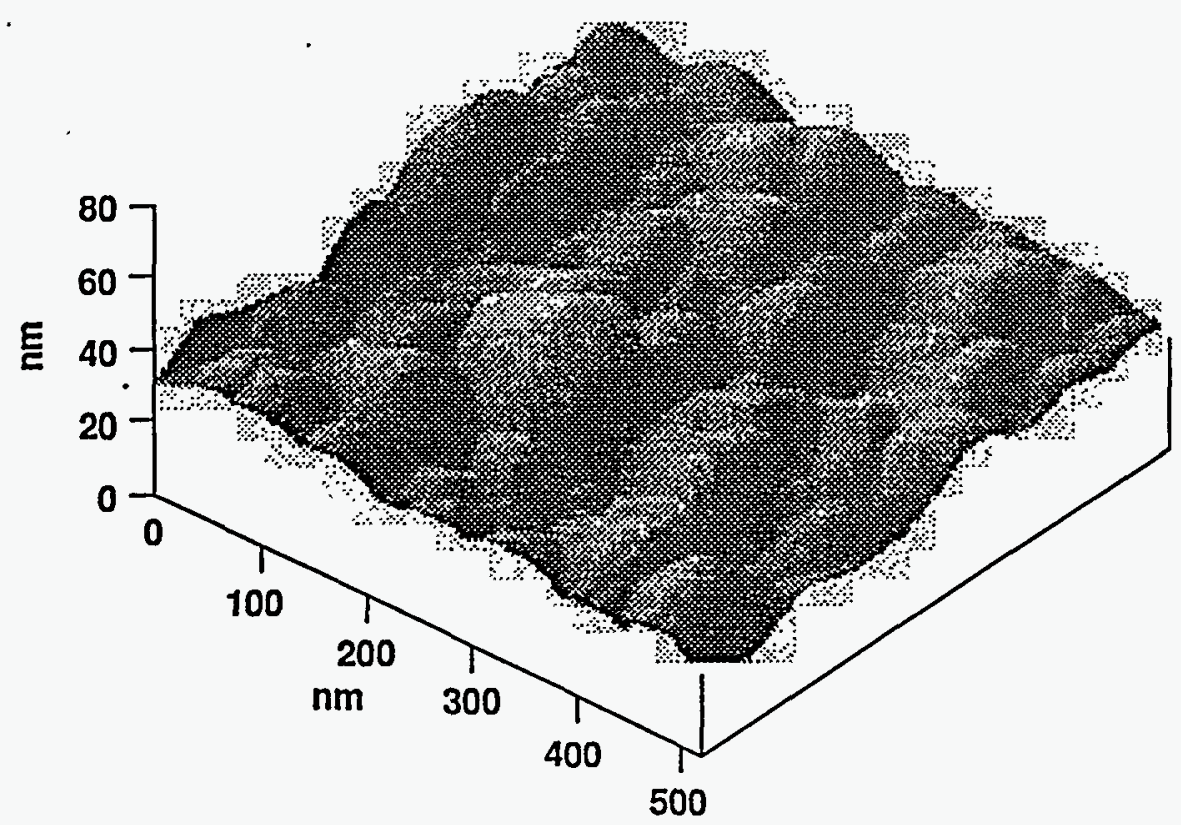

Figure 5. Atomic force measurement of LLNL produced DLC surface.

The second observation we have made also appears important for PLD. The deposition rate of DLC scales with pulse repetition rate (at least to $4.4 \mathrm{kHz}$ ). This appears obvious, and in fact, is largely what motivated us in the first place to try PLD with the copper vapor lasers.

The third observation we have made is an improved surface character in our deposition tests. While this observation is semi-quantitative for the moment, our deposition regime is significantly different because of lower pulse energies ( $23 \mathrm{~mJ}$ versus 0.5 to $2 \mathrm{~J}$ ) and higher repetition rates ( $4.4 \mathrm{kHz}$ versus 10 to $20 \mathrm{~Hz}$ ). We have found that we can produce good looking material as long as we have no more than 10 to 20 laser pulses on the same spot on the target. Based on our observations and modeling 12 , this should be no more than 2 to 3 microns in depth in the graphite. We believe, as others, that much deeper target penetration leads to explosive removal of macroparticles, particularly around the spot periphery.

\section{Engineering Issues for High Rate PLD Hardware}

Several potential issues associated with a high rate PLD system have been encountered in our small system. One issue, mentioned earlier, is protection of the laser window from coating by the ablated material. We have found that commercially available $2.5 \mu \mathrm{m}$ thick mylar film that could be continuously advanced past the vacuum side of the window minimally affects the laser beam quality, and, if refreshed every $5 \times 0^{4}$ laser pulses, does not lead to loss of laser power. A reel-toreel system for moving fresh film is commercially available.

The second engineering issue requiring attention is the development of a means for rapidly replacing the target material. The power densities and high-pulse rates used in our scoping studies rapidly damage the ablation target surface. After more than 20 pulses strike a single area, we begin to see evidence for the ejection of macroparticles which in most cases are not desired on the finished coating. In practical terms, this means that with a $300 \mu \mathrm{m}$ diameter laser spot on the target, we damage approximately one linear inch of one-inch diameter rod every $3.5 \times 10^{5}$ shots 
(or every 80 seconds). The development of hardware to introduce virgin target material through a vacuum load locking system appears to be straightforward.

Similarly, at our projected deposition rates, a method for moving the substrate relative to the target to produce uniform coatings and a method to rapidly change out substrates will be required for a continuous production process. The requirement for short substrate change out time may be alleviated by multiplexing one laser source-to several deposition chambers, potentially through optical fibers. Optical fibers may also allow development of a robotic structure that could deposit material inside large structures, either contained in a vacuum chamber or with its own vacuum system.

\section{Summary}

A promising pulsed laser deposition technology utilizing visible light has been demonstrated. Trial runs producing diamond-like-carbon have been encouraging. This technology appears to have significant advantages over other methods in deposition rate and surface morphology. More work is required to understand the physical characteristics of these coatings to verify their utility.

Several proposed uses of DLC, or crystalline diamond films are: (1) low work function emitters for flat panel displays, (2) hard low-friction coatings for machine tool bits or infrared optics, and (3) corrosion resistant coatings for chemical processing systems.

One of the distinct advantages of the PLD process is the near stoichiometric transfer from the ablation target to the desired substrate. We believe that the use of high repetition rate visible lasers allows high deposition rates and consequently a relatively inexpensive coating technique for a large number of high value thin films. Table 2 serves as an indication of potential thin-film systems and their applications.

Table 2. Materials with difficult stoichiometries that have been successfully coated by PLD.

\begin{tabular}{|c|c|c|}
\hline Material & Laser & Use \\
\hline $\mathrm{BaFe}_{16} 0_{19}$ & $\mathrm{KrF}$ & High density hard disk coatings \\
\hline $\mathrm{BaTiO}_{3}$ & Nd:YAG & Optical coatings \\
\hline Cubic BN & $\mathrm{KrF}$ & $\begin{array}{l}\text { High temperature, radiation resistant semiconductors } \\
\text { Cutting tool coatings }\end{array}$ \\
\hline Amorphic C & $\begin{array}{l}\mathrm{Nd}: Y A G \\
\mathrm{XeCl}\end{array}$ & $\begin{array}{l}\text { Tribological coatings } \\
\text { Heat sinks } \\
\text { Field emitters for FPD's }\end{array}$ \\
\hline $\mathrm{Cd}_{\mathrm{x}} \mathrm{Z}_{1-\mathrm{x}} \mathrm{Te}$ & $\mathrm{KrF}$ & Ir detectors \\
\hline $\mathrm{CoSi}_{2}$ & $\mathrm{KrF}$ & Low resistivity interconnects for fast switching Schottky rectifiers \\
\hline $\mathrm{MoS}_{2}$ & $\mathrm{XeCl}$ & High resistivity lubricating coating \\
\hline $\mathrm{NbSe}_{2}$ & $\mathrm{KrF}$ & Low resistivity lubricating coating \\
\hline $\mathrm{Pb}\left(\mathrm{Zr}_{0.54} \mathrm{Ti}_{0.46}\right) 0_{3}$ & $\begin{array}{l}\text { ArF } \\
\text { Nd:YAG }\end{array}$ & $\begin{array}{l}\text { Piezoelectric devices } \\
\text { Non volatile memory }\end{array}$ \\
\hline $\mathrm{SiC}$ & $\mathrm{XeF}$ & High temperature, wide band gap semiconductors \\
\hline $\mathrm{TiO}_{2}$ & $\mathrm{KrF}$ & Antireflection coatings \\
\hline $\mathrm{YBa}_{2} \mathrm{Cu}_{3} \mathrm{O}_{7}$ & $\mathrm{ArF}, \mathrm{KrF}$ & High Tc superconductors \\
\hline $\mathrm{ZnO}$ & $\begin{array}{l}\mathrm{KrF} \\
\mathrm{Nd}: Y A G(2 \mathrm{x})\end{array}$ & $\begin{array}{l}\text { Piezoclectric devices } \\
\text { Phosphors }\end{array}$ \\
\hline
\end{tabular}




\section{Acknowledgments}

We wish to thank LLNL scientific staff W. J. Siekhaus and M. Balooch for the AFM measurements (Fig. 5) as well as M. A. Schildbach and G. A. Meyer for the EELS measurements (Figs. 2 ). We also wish to thank Louis Bernandez at Sandia National Laboratory, California, for the measurement of Raman spectra (Fig. 3). G. Huete, J. Poulter, and M. Solarski provided excellent support in the laboratory. R. Paris and J. Sullivan were instrumental in helping with electrical control aspects of the experiments.

Work performed under the auspices of the U.S. Department of Energy by Lawrence Livermore National Laboratory under Contract W-7405-Eng-48.

\section{References}

1. (a) Mat. Res. Soc. Symp. Proc., Vol 191, Ed. by D.C. Paine and J.C. Bravman, 1990, Pg. 3, 129, 141, 147, 153, 159, 165, 171, 183, 199, 205, 211, 217. (b) Mat. Res. Soc. Symp. Proc., Vol 285, Ed. by B. Baren, J.J. Dubowski, and D.P. Norton, 1993, Pg. 15, 27, 33, $51,263,269,281,293,299,305,311$.

2. (a) Mat. Res. Soc. Symp. Proc., Vol 191, Ed. by D.C. Paine and J.C. Bravman, 1990, Pg. 25, 31. (b) Mat. Res. Soc. Symp. Proc., Vol 285, Ed. by B. Baren, J.J. Dubowski, and D.P. Norton, 1993, Pg. 87.

3. (a) C.B. Collins et al., Appl. Phys. Lett. 54 (1989), 216. (b) Mat. Res. Soc. Symp. Proc., Vol 285, Ed. by B. Baren, J.J. Dubowski and D.P. Norton, 1993, Pg. 215, 447, 547, 557.

4. Mat. Res. Soc. Symp. Proc., Vol 285, Ed. by B. Baren, J.J. Dubowski and D.P. Norton, 1993, Pg. 27, 39, 117, 507, 513.

5. (a) Mat. Res. Soc. Symp. Proc., Vol 191, Ed. by D.C. Paine and J.C. Bravman, 1990, Pg. 19, 43. (b) Mat. Res. Soc. Symp Proc., Vol 285, Ed. by B. Baren, J.J. Dubowski and D.P. Norton, 1993, Pg. 263, 355.

6. C.M. Cotell et al, Patent Pending, Docket No. N.C., 73, 252.

7. S. Amirhagi et al., Mat. Res. Soc. Symp. Proc., 285 (1993), 489.

8. P.T. Murray and D.J. Peeler, J. Elec. Materials (submitted).

9. H.C. Tsai and D.B. Bogy, J. Vac. Sci. Technol. 5 (1987), 3287.

10. K. Saijo et al., Mater. and Manuf. Proc., 8 (1993), 59.

11. X. Chen and J. Narayan, Mat. Res. Soc. Symp. Proc., 286 (1993), 391.

12. C. D. Boley, "Computational Model of Drilling with High Radiance Pulsed Lasers," ICALEO (1994). 


\section{Authors' Biographies}

William McLean, II received his Ph.D. in Physical Chemistry from the University of North Carolina, Chapel Hill, in 1977. He has over 20 years of experience with thin-film coatings and surface characterization technology. He currently leads a group in advanced materials technology at Lawrence Livermore National Laboratory.

Bruce E. Warner received his Ph.D. in Physics from the University of Colorado, Boulder, in 1979. He has over 15 years experience in gas discharge physics, ultraviolet and visible laser technology, and materials processing. He is currently Associate Program Leader for Laser Materials Processing at Lawrence Livermore National Laboratory.

Edward J. Fehring is an Engineering Technical Associate at Lawrence Livermore National Laboratory with 25 years of experience in materials processing and characterization. His recent activities have included the testing of high-temperature corrosion resistant coatings and design of high-throughput laser deposition systems.

Ernest P. Dragon is a Staff Engineering Associate at Lawrence Livermore National Laboratory. He has a mechanical engineering background with 25 years experience in laser technology and optical system design. 
Technical Information Department • Lawrence Livermore National Laboratory University of California • Livermore, California 94551

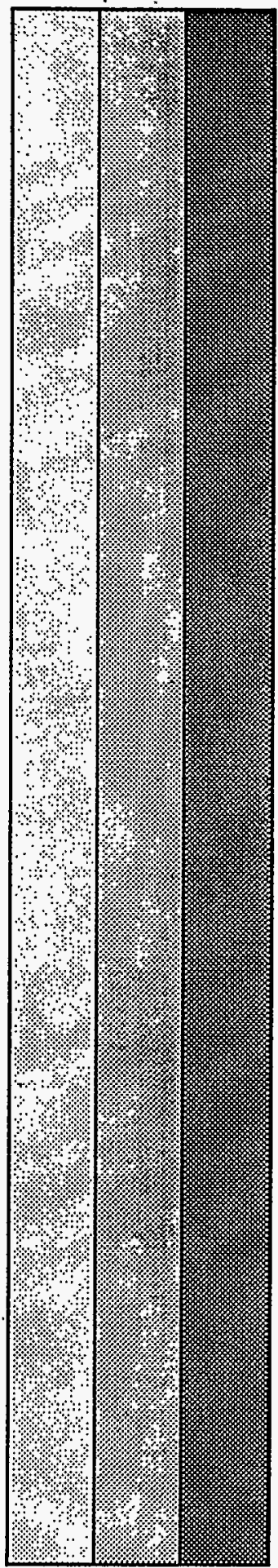

